\begin{tabular}{l} 
Sharif University of Technology \\
Scientia Iranica \\
SCIENTIA \\
IRAN \\
Thansactions A: Civil Engineering \\
\hline
\end{tabular}

\title{
Experimental investigation of the effect of winged sleeper on lateral resistance of ballasted track
}

\author{
J.A. Zakeri* and H. Hassanrezaei \\ Center of Excellence in Railway Transportation, Iran University of Science and Technology, Narmak, Tehran, P.O. Box \\ 16846-13114, Iran.
}

Received 13 April 2019; received in revised form 16 December 2019; accepted 20 April 2020

\section{KEYWORDS \\ Railway track; \\ STPT; \\ Lateral Track Panel \\ loading Test (LTPT); \\ Lateral resistance; \\ Winged sleeper.}

\begin{abstract}
Nowadays, the advantages of continuous welded rails and engineers' preference for such types of tracks have highlighted the significance of the lateral stability of railways. In order to promote the stability of railways, lateral resistance development mechanism should be reinforced. One of the methods for reinforcing the mechanism of passive pressures at the end of sleeper and consequently, increasing the durability of tracks is utilization of winged sleepers. In this paper, the lateral resistance of conventional and winged sleepers is examined and compared using laboratory and field tests. The lateral resistant force of tracks was measured by single-sleeper push test and track panel loading test. At a laboratory, in comparison with the conventional samples, single-sleeper push tests showed a $101 \%$ increase in the lateral resistance of the winged sleeper. In the field test, the test track was divided into three parts, namely conventional sleeper, winged sleeper, and mixed parts (alternating between conventional and winged sleepers). The lateral resistance of each part was measured by Lateral Track Panel loading Test (LTPT). In the field test, a $96 \%$ increase in lateral resistance was obtained. In comparison with the conventional panels, winged-sleeper panels and mixed-sleeper panels showed $71 \%$ and $59 \%$ resistance increases, respectively. While using winged sleepers in ballasted tracks, lateral displacements decreased by increasing the volume of shoulder and crib ballasts through the passive pressure mechanism.
\end{abstract}

(C) 2021 Sharif University of Technology. All rights reserved.

\section{Introduction}

Rail track forces are exerted in three directions, namely vertical, longitudinal, and lateral. In each direction, the resistance required the forces should be supplied. Vertical forces are the design basis of rail tracks. It is also necessary to control track stability in longitudinal and lateral directions. An increase in the lateral forces of Continuous Welded Rail (CWR) tracks leads to faster deterioration of their geometry and consequently,

*. Corresponding author.

E-mail address: zakeri@iust.ac.ir (J.A. Zakeri)

doi: $10.24200 /$ sci.2020.53320.3184 increase in the maintenance and costs. The lateral resistance of ballasted tracks is provided by rail, fastener, and interaction between sleeper and ballast, with the latter playing the key role $[1,2]$.

Ballast resistance versus lateral load is composed of three parts: base friction of the sleeper, side friction of the sleeper, and passive pressure at the end of the sleeper [3]. These parts are shown in Figure 1.

\subsection{Methods for increasing lateral resistance} Better understanding of the resistance mechanism in each of these three mentioned parts under some alterations can play a key role in increasing lateral resistance. In his study on ballasts, Le Pen and Powrie [4] examined the relative contributions of the 


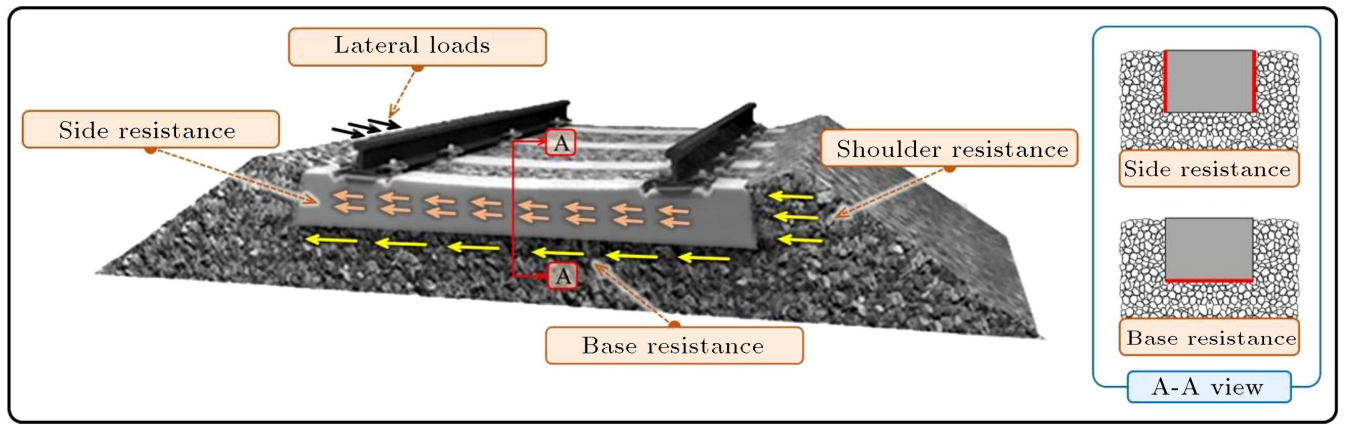

Figure 1. Lateral resistance component caused by the interaction of sleeper and ballast.

base, crib behavior, and shoulder ballast to lateral resistance from a geotechnical point of view. Many different methods have been suggested and studied to decrease the lateral displacements of tracks. Generally, the methods for increasing the lateral resistance can be divided into three groups:

a) Changing the material, shape, and dimensions of track components The first group of methods can increase the lateral resistance by improving the interaction between the sleeper and ballast. The concept of changing the shape of sleepers, including twin block sleeper [5] and frictional sleeper [6], was studied and the lateral resistance could increase by about 30 and $65 \%$, respectively. Adding vertical stiffeners to the bottom of steel sleepers and increasing the interaction between the sleeper and its bottom ballast could increase the lateral resistance by $140 \%$ by reinforcing the mechanism of the passive pressures at the bottom of the sleeper [7].

b) Utilizing new technologies in the existing railway tracks: Utilizing new technologies in the existing railway tracks with the objective of decreasing the lateral displacements is the second method, which could increase lateral resistance. Sabaghi [8] conducted STPTs and showed that use of sleeper anchors could increase the lateral resistance up to $19 \%$. Other factors that can affect the lateral resistance are use of polyurethane bonding method [9], Under Sleeper Pads (USP) [10], geosynthetics [11], and baby gabion [12]. The effect of geogrid on the lateral resistance was investigated by implementing STPT and Lateral Track Panel loading Test (LTPT). The STPTs in the lab and field confirmed more than $31 \%$ and $42 \%$ increase in the single-tie lateral resistance for ballast layers reinforced by one and two geogrid layers, respectively; however, these values reached $29 \%$ and $40 \%$ in the case of LTPT [13]. Substituting the rail track shoulder by baby gabions, which surround ballast particles and prevent their movement, increased the lateral resistance by about $40 \%$. Moreover, the consumed ballast volume was reduced by about $35 \%$ [12].

c) Changing the track geometry and maintenance plan: Changing the track geometry and maintenance plan is the third group of methods aimed at improving the lateral behavior. Kabo [14] conducted 3D elastoplastic simulations of ballast deformation with a focus on lateral resistance. Ballast geometry, vertical and lateral loading, and friction between the ballast and sleeper would vary in a parametric study. Increasing the shoulder width had a significant effect on the lateral resistance. An increase in the shoulder width could increase the volume and weight of the resisting wedge against the lateral displacement of the sleeper $[1,15]$. Track resistance would decrease after tamping operation and mechanical stabilization of the track could compensate for a part of the lost resistance [16].

The results of the studies on the lateral resistance are presented in Table 1.

\subsection{Winged sleeper}

Winged sleeper is another example of the methods that improves the lateral behavior of sleepers by changing the geometry of sleepers and adding some excrescences to the sides. The differences between conventional and winged sleepers are shown in Figure 2. While an increase in the weight of the sleeper leads to a greater bottom friction, an increase in the width of the sleeper increases the resisting ballast volume of the shoulder. The volume of the crib ballast results in higher resistance. Winged sleeper has a proper performance against vertical loads. Better stress contribution is

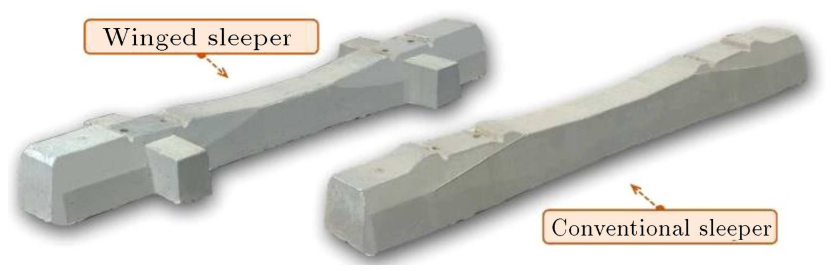

Figure 2. Conventional and winged sleepers. 
Table 1. Results of lateral resistance changes for different methods.

\begin{tabular}{cccc}
\hline Category & Studied item & Difference (\%) & Reference \\
\hline $\begin{array}{c}\text { Changing the material, shape, } \\
\text { and dimensions of track } \\
\text { components }\end{array}$ & Twin block sleeper & 30 & Profillidis [5] \\
& Frictional sleeper & 65 & Zakeri et al. [6] \\
Steel sleepers with vertical stiffeners & 140 & Zakeri and Talebi [7] \\
\hline $\begin{array}{c}\text { Utilizing new technologies } \\
\text { in the existing }\end{array}$ & Sleeper anchors & 19 & Sabaghi [8] \\
railway tracks & Polyurethane bonding method & $100 \sim 184$ & Jing et al. [9] \\
& Under sleeper pads & 20 & Pucillo et al. [10] \\
Baby gabion & Geogrid & 40 & Darkhosh [12] \\
Changing track geometry & Increasing ballast shoulder & $15 \sim 20$ & Kabo [14] \\
and maintenance plan & Tamping operation & $16 \sim 22$ & Zakeri et al. [15] \\
& Mechanical stabilization & -43 & Sussmann et al. [16] \\
& & 31 & Sussmann et al. [16] \\
\hline
\end{tabular}

expected in the winged-type sleeper with respect to the increased area under loading. Reduced vertical stresses and better stress contribution in the ballast area would decrease subsidence, increase the stability of the track geometry, shorten maintenance periods, and lessen maintenance costs.

Winged sleeper was designed and built in Austrian Federal Railways (ÖBB) in 1972 [17]. It provided a low-radius curvature (including conventional and winged sections) to examine the performance of new sleepers and record lateral displacement upon heating the rail. In this examination, for a 60 centigrade increase in the rail temperature, $1.2 \mathrm{~mm}$ lateral displacement in the winged sleeper track was recorded. In an identical track with a conventional sleeper, the lateral displacement was $6.5 \mathrm{~mm}$. Moreover, investigation of the resistance load of the winged sleeper in comparison with the conventional sleeper of Be14 in the ballast bed simulator under dynamic load showed an average increase of $116 \%$ in lateral resistance of the winged sleeper [18]. A numerical model of a new sleeper with some prominence on the bottom was developed to examine the lateral displacements of the actual curves as a result of temperature changes. A comparison of the results of the lateral displacement showed that the lateral displacement for the new sleeper was $55 \%$ less than that for the timber sleeper and 53\% less than that for the conventional concrete sleepers [19]. Furthermore, in the studies on the lateral resistance of sleeper and ballast in a track test with one-fifth scale, the lateral resistance of the winged sleepers was compared with that of the conventional sleepers. STPT was performed on latter sleepers. In addition, $4 \mathrm{~mm} / \mathrm{min}$ displacements were considered and data from 0 to $10 \mathrm{~mm}$ were recorded. The obtained results showed 40-90\% increase in the lateral resistant force for different types of winged sleepers compared with the simple ones (the geometry and different sizes of sleepers were taken into account) [20].

\subsection{Measuring methods of lateral resistance}

The resistance of tracks against lateral displacements is measured by different methods [21]. The most conventional methods are STPT and LTPT.

In the single-sleeper method, a sleeper is put into the rail track. In this method, the test sleeper is disconnected from the rest of the track and a hydraulic jack applies the loading to one of the rails, the reaction of which affects the sleeper. On the contrary, a Linear Variable Displacement Transducer (LVDT) is installed on the other rail and records the lateral displacement of the sleeper. Schematic setup of STPT is depicted in Figure 3.

In the LTPT method, the load is applied to a group of sleepers and rails in the panel shape and then, they are displaced laterally. According to the loaddisplacement behavior, the lateral resistance of track is estimated. LTPT is schematically depicted in Figure 4.

In this paper, the lateral resistance of conventional sleepers (B70) and winged sleepers (B70w) was estimated through laboratory and field examinations. STPT was performed to examine the performance of a winged sleeper in comparison to its conventional type. LTPT was also performed to examine the lateral performance of the winged and conventional sleepers installed on a track panel.

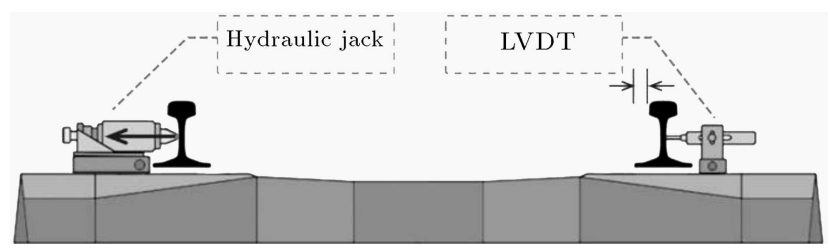

Figure 3. Schematic setup of Single Tie Push Test (STPT). 


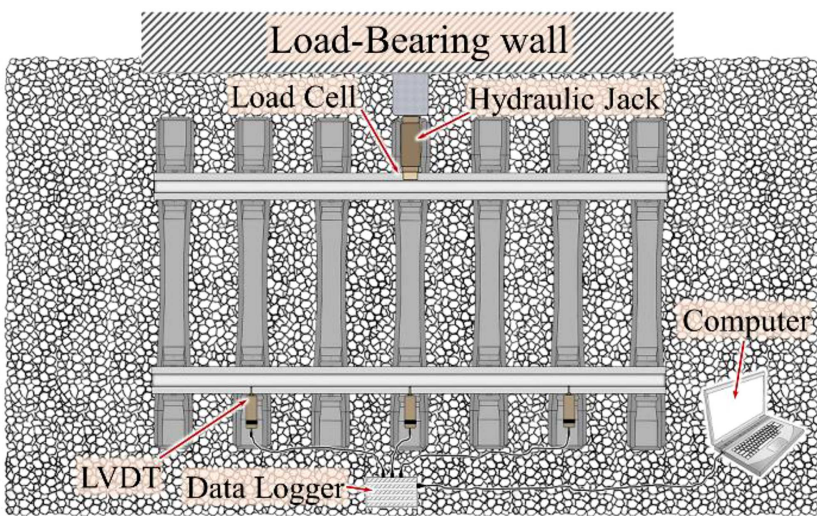

Figure 4. Schematic setup of Lateral Track Panel loading Test (LTPT).

\section{Laboratory examination of winged sleeper's lateral resistance}

\subsection{Preparing the test track}

A full-scale sample with a length of $3 \mathrm{~m}$ was built to perform STPT. Geometrical parameters of the track including the shoulder width of $40 \mathrm{~cm}$ and ballast height under the sleeper of $30 \mathrm{~cm}$ were chosen in the School of Railway Engineering (SRE) track laboratory. The interspace of the sleepers was $60 \mathrm{~cm}$. Ballast layers with a thickness of $10 \mathrm{~cm}$ were poured and each layer was rolled 25 times with a $29-\mathrm{kg}$ laboratory roller. The sleeper used in the test was a B70 in which four wings were fixed on the sides. The dimensions of the sleeper are given in Figure 5. The wings increased the total weight of the sleeper from $280 \mathrm{~kg}$ to about $325 \mathrm{~kg}$.

\subsection{STPT results}

STPT was performed as described in Section 1.3 to examine the resistive force versus lateral load. To this end, KS625N that comprised hydraulic jack, LVDT, and processor was utilized. Figure 6 shows the installed equipment of the test. In the laboratory examination, the resistance of a B70 sleeper was measured by implementing a lateral load and recording the corresponding lateral displacements. Figure 7 shows the load-displacement diagram for B70 and B70w sleepers.

According to the diagram, compared to the B70 sleeper with the resistive force of $7.38 \mathrm{kN}$, the $\mathrm{B} 70 \mathrm{w}$

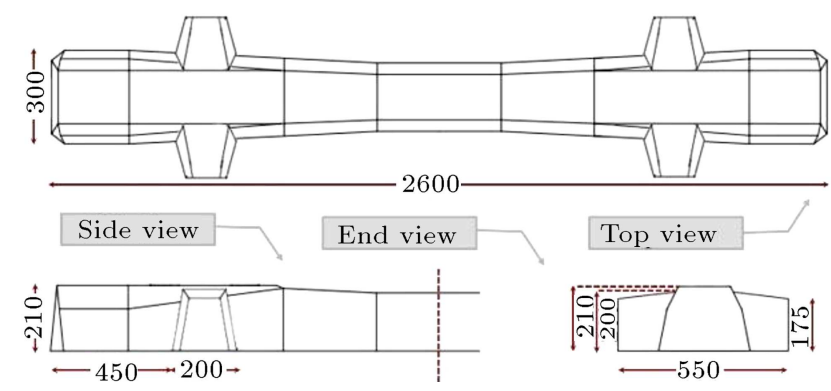

Figure 5. Sleeper dimensions in the laboratory study.

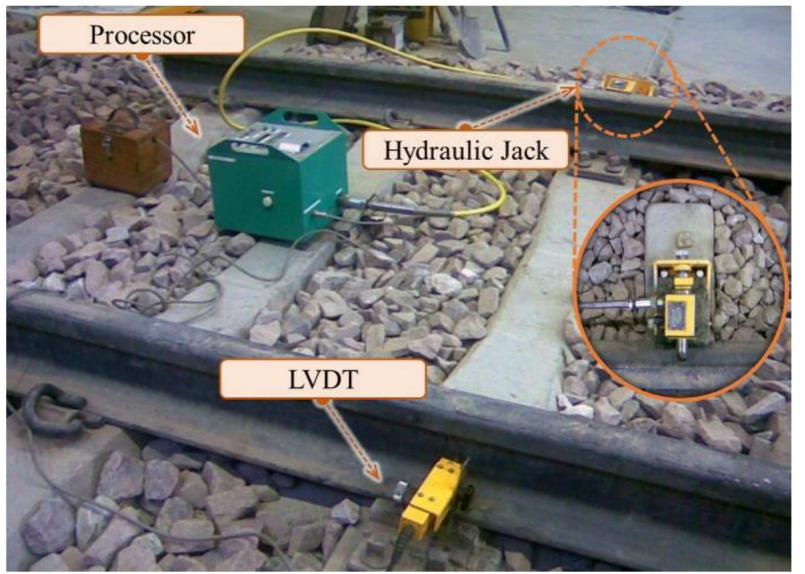

Figure 6. The installed equipment of the laboratory examination.

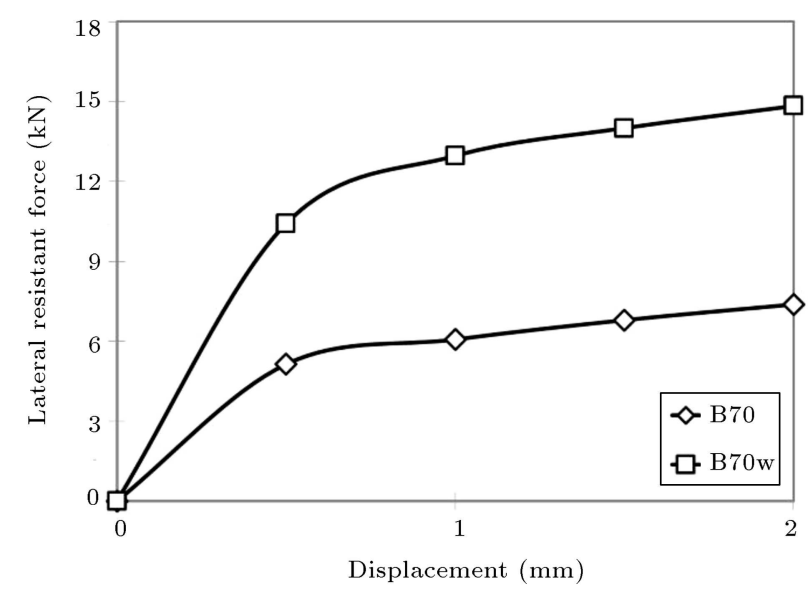

Figure 7. Lateral resistant force of B70 and B70w sleepers in the laboratory Single Tie Push Test (STPT).

winged sleeper with the resistive force of $14.84 \mathrm{kN}$ showed a $101 \%$ increase in the lateral resistance for lateral displacement of $2 \mathrm{~mm}$.

\section{Field examination of winged sleeper's lateral resistance}

\subsection{Preparing the test track in the field}

The track considered in this study is one of the currently active tracks in Karaj Railroad Station. This track has concrete sleepers and UIC60 rails. The ballast height under the sleeper is about $30 \mathrm{~cm}$, measured after reconstruction of the track. Since the existing ballast is loose and has low density, a new ballast is used when installing the winged sleepers, which is ordinarily low in density. Use of new ballast causes critical conditions in which the resistance of the track is lower than before. A part of the track with a length of $18 \mathrm{~m}$ was selected and divided into three sections with equal lengths of $6 \mathrm{~m}$ length including 10 sleepers. The first section was equipped with the conventional concrete sleeper, B70. The second section was an 


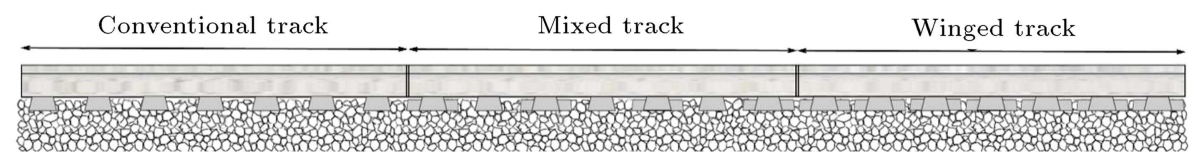

Figure 8. Conventional, mixed, and winged sections on the test track.

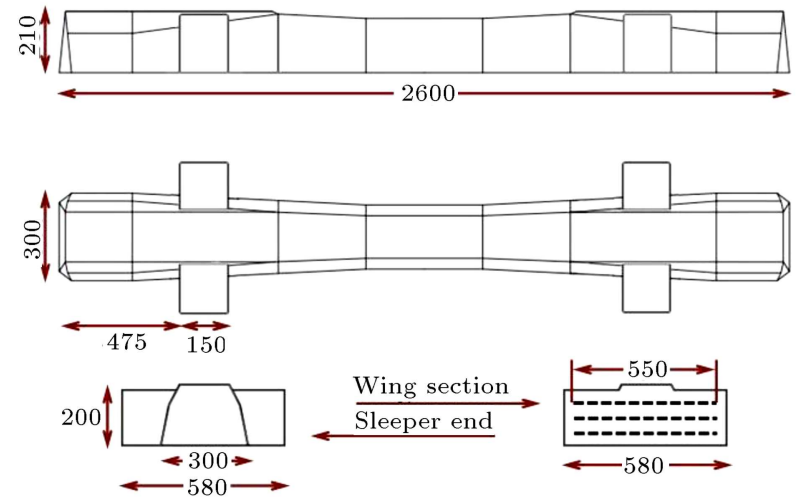

Figure 9. Sleeper dimensions in the field study.

alternate mixture of B70 and B70w sleepers. The third section was equipped with B70w sleepers. In all of the laboratory and field tests, the center-to-center sleeper spacing was set to $60 \mathrm{~cm}$. In order to implement the panel with a specific number of sleepers, the additional sleepers were separated from the rest of the panel. The length of the panel in all the states with 5,7 , and 9 sleepers was $3,4.2$, and $5.4 \mathrm{~m}$, respectively. Figure 8 shows the three aforementioned sections.

There are slight differences between the winged sleeper used in field tests and the ones used in the laboratory in terms of manufacturing reasons. This sleeper was built by the RSTC Company. These wings of the sleepers were reinforced to prevent probable detachment from the body. Winged sleeper, B70w, is schematically depicted in Figure 9.

According to the prior planning, two STPTs and nine LTPTs were performed in order to examine the effect of winged sleepers on the lateral stability of the railroad. The results of these tests were carefully examined. In each of these three sections, LTPT was performed on the panels with five, seven, and nine sleepers. In the LTPT, force was exerted on the rail via hydraulic jack, the lateral displacements of the panel were recorded at 3 different points, and the average amount was considered as the panel's lateral displacement.

\subsection{STPT field results}

Lateral resistance forces were measured using STPT in field. The load-displacement diagram for B70 and B70w sleepers is shown in Figure 10.

The measured resistance force for the 2-mm lateral displacement was $12.92 \mathrm{kN}$ for the winged sleeper and $6.59 \mathrm{kN}$ for the conventional sleeper. According to this diagram, the lateral resistance force of $\mathrm{B} 70 \mathrm{w}$
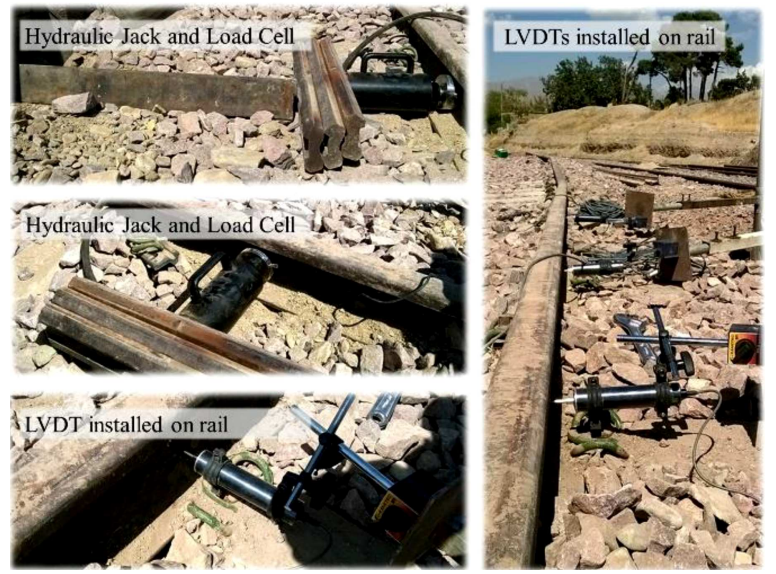

Figure 10. Hydraulic jack and Linear Variable Displacement Transducers (LVDTs) in Lateral Track Panel loading Test (LTPT).

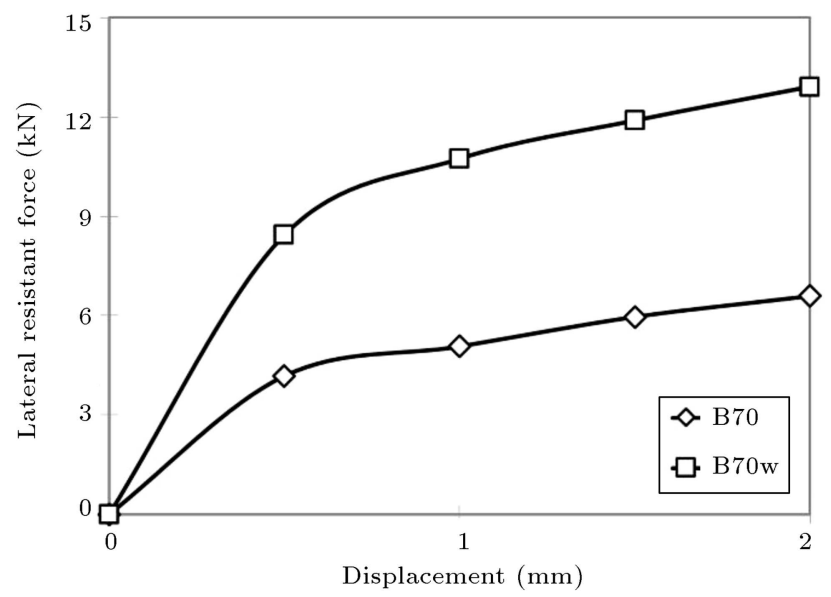

Figure 11. Single Tie Push Test (STPT) field results for B70 and B70w sleepers.

was 1.96 times more than that of the conventional B70 sleeper. A $96 \%$ increase in the lateral resistance was observed throughout this test. In this study, a $101 \%$ increase in the lateral resistance force of the winged sleeper, in comparison with the conventional sleeper, was obtained at the laboratory. Figure 11 shows the load-displacement diagram for B70 and B70w sleepers.

\subsection{LTPT field results}

As mentioned earlier, nine discrete panels were tested on three differently prepared sections. The test results of the conventional, winged, and mixed panels are presented in Figures 12, 13, and 14, respectively.

In order to compare the lateral performance of each of the studied cases, the lateral resistance force 


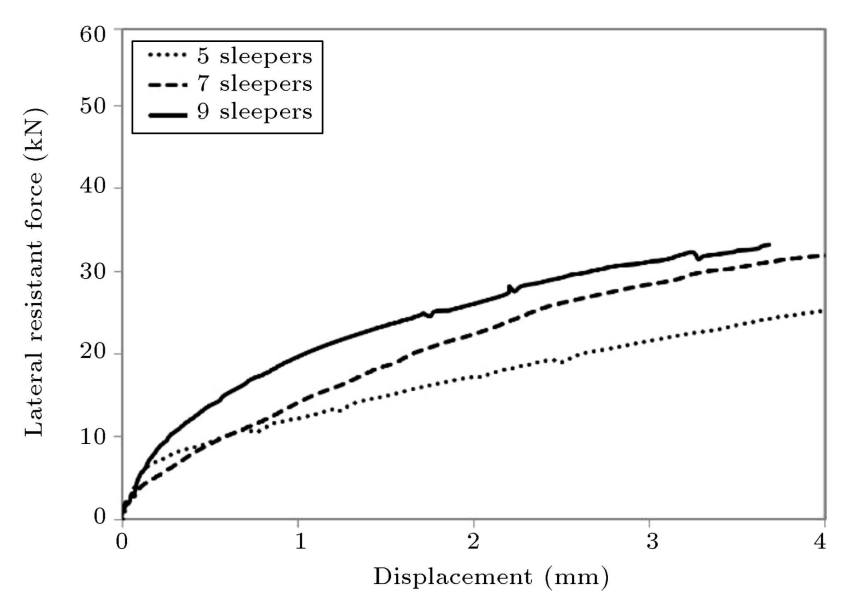

Figure 12. Lateral resistance force of conventional panels in the field test.

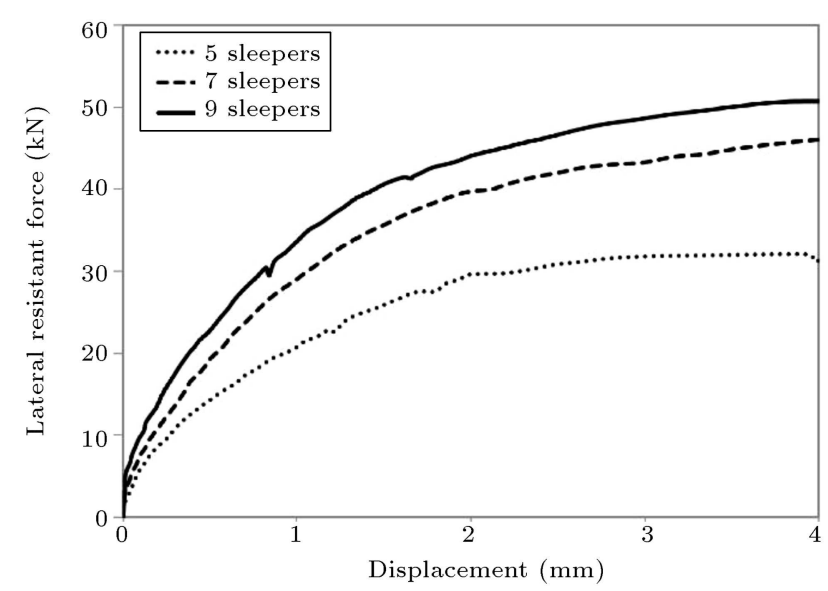

Figure 13. Lateral resistance force of winged panels in the field test.

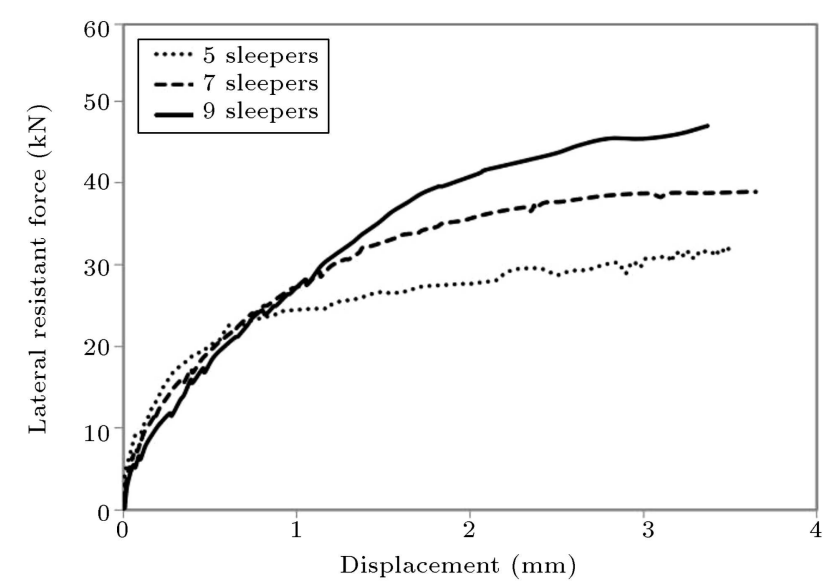

Figure 14. Lateral resistance force of mixed panels in the field test.

corresponding to the 2-mm lateral displacement was extracted for all these cases. The lateral resistance forces corresponding to the 2-mm lateral displacement are presented in Table 2 .

According to Table 2, the increased resistance

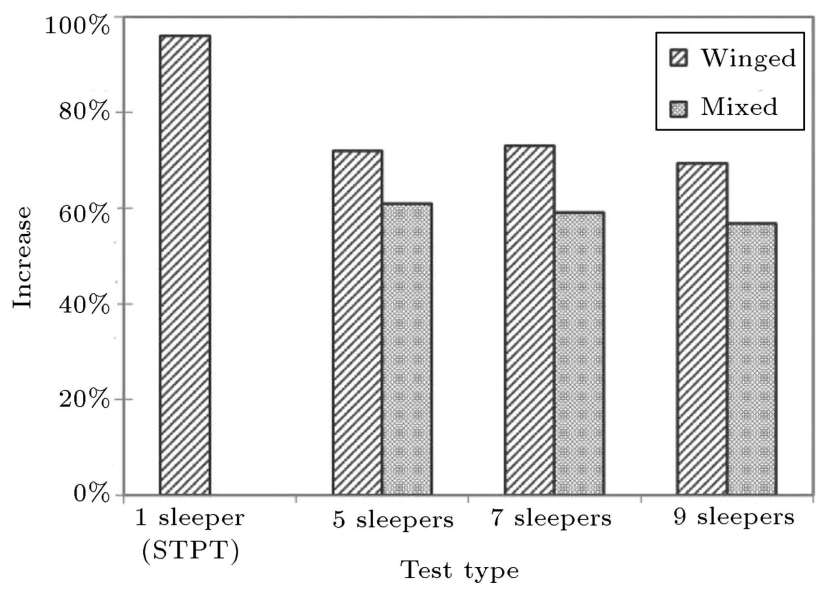

Figure 15. Increased resistance of winged and mixed sleepers compared with conventional types.

of the panels equipped with winged sleepers and also mixed sleepers, compared with conventional sleepers, was obtained, as drawn in Figure 15. In this figure, the increase in lateral resistance force of the winged sleeper compared with the conventional sleeper, obtained from $\mathrm{STPT}$, is also presented in terms of percentage.

\section{Discussion}

\subsection{Comparing the obtained results with those of previous studies}

A comparison between the results of STPT in this study and those of previous studies proved the significant role of winged sleepers in improving the lateral stability of the railway. To this end, the increase rates of $96 \%$ and $101 \%$ in this study, the increase of $116 \%$ in the study of Austria's Federal Railroad [18], and the increase of $40-90 \%$ in the study of Koike et al. [20] were observed.

The results were different due to the differences in the dimensions of sleepers and wings, in the type of tests, and also in geometry and quality of the test track (including sleeper distance, shoulder size, etc.).

\subsection{Comparing STPT laboratory and field results}

This study showed that in comparison with the lateral resistance of the conventional sleepers, that of the winged sleepers increased by $96 \%$. A review of the laboratory test results showed a $101 \%$ increase in the lateral resistance of the winged sleepers, compared with the conventional sleepers. In addition, good agreement between these test results was observed. Both laboratory and field tests were on the full scale and their results confirmed the satisfactory lateral performance of the winged sleepers. The values of the lateral resistance and the percentage change of the STPTs are presented in Table 3 .

The resistance force at the end of the sleeper can be measured by calculating the friction changes at the 
Table 2. Lateral resistance force in $2 \mathrm{~mm}$ lateral displacement $(\mathrm{kN})$.

\begin{tabular}{lccccc}
\hline Track type $\boldsymbol{\nabla}$ & Test type $\boldsymbol{1}$ & $\begin{array}{c}\text { 1 sleeper } \\
\text { (STPT) }\end{array}$ & $\begin{array}{c}\text { 5 sleepers } \\
\text { (LTPT) }\end{array}$ & $\begin{array}{c}\text { 7 sleepers } \\
\text { (LTPT) }\end{array}$ & $\begin{array}{c}\text { 9 sleepers } \\
\text { (LTPT) }\end{array}$ \\
\hline Conventional & 6.59 & 17.19 & 22.40 & 26.40 \\
Mixed & - & 27.65 & 35.63 & 40.82 \\
Winged & 12.92 & 29.57 & 38.76 & 44.11 \\
\hline
\end{tabular}

Table 3. Single Tie Push Test (STPT) laboratory and field results.

\begin{tabular}{lccc}
\hline & Conventional & Winged & $\begin{array}{c}\text { Difference } \\
(\%)\end{array}$ \\
\hline Laboratory & 7.38 & 14.84 & 101 \\
Field & 6.59 & 12.92 & 96 \\
\hline
\end{tabular}

bottom of the sleeper as well as its sides; in this respect, the effect of the wings on the lateral resistance can be determined. The following assumptions were made to estimate the resistance force at the bottom as well as the sides, which share some similarities with the calculations done by Le Pen $[4,22]$ according to the test track conditions:

$$
\begin{aligned}
& \gamma=15 \mathrm{kN} / \mathrm{m}^{3}, \quad \phi=45 \mathrm{deg}, \quad \delta=24 \mathrm{deg}, \\
& A_{\text {side-B }}, \quad A_{\text {side }-B 70}=0.92 \mathrm{~m}^{2}, \quad 1.04 \mathrm{~m}^{2}
\end{aligned}
$$

where $\gamma$ is the density of the ballast, $\phi$ is the internal friction angle of the ballast, $\delta$ is the frictional resistance angle at interfaces (e.g., ballast to sleeper), and $A_{\text {side }}$ is the contact area of both the sleeper and ballast.

The friction forces of the winged and conventional sleepers were calculated as 2.87 and $2.47 \mathrm{kN}$, respectively. Moreover, according to the following calculations, the resistance force of the sides of the winged and conventional sleepers was fixed at 1.24 and $1.4 \mathrm{kN}$, respectively:

$$
\begin{aligned}
& k=(1+\sin \phi) /(1-\sin \phi)=2 \\
& \sigma_{v}=\gamma h / 2=1.5 \mathrm{kN} / \mathrm{m}^{3} \\
& \sigma_{h}=k \sigma_{v}=3 \mathrm{kN} / \mathrm{m}^{3} \\
& F_{h}=\sigma_{h} \times A_{\text {side }}, \\
& \rightarrow F_{h-B 70 w}=2.76 \mathrm{kN}, \text { and } F_{h-B 70}=3.12 \mathrm{kN} \\
& R_{\text {side }}=F_{h} \times \tan \delta \\
& \rightarrow R_{\text {side-B }},
\end{aligned}
$$

The obtained values are in the same range as those of the previous studies [23]. After estimating the resistance of the bottom and the sides of the sleepers, the end resistance in both sleepers is obtained as follows:

$$
\begin{aligned}
& R_{\text {end }}=R_{\text {total }}-R_{\text {bottom }}-R_{\text {side }} \\
& \rightarrow R_{\text {end-B }-B 0 w}=8.73 \mathrm{kN}, \text { and } R_{\text {end }-B 70}=2.70 \mathrm{kN} .
\end{aligned}
$$

As mentioned earlier, increasing the lateral resistance is achieved by reinforcement of the friction at the bottom and sides of the sleepers as well as the mechanism of passive pressure. In this study, the friction at the bottom and sides of the sleepers slightly varied and the lateral resistance increased due to the mechanism of passive pressure of the ballast. Any increase in the width of the sleeper would increase the volume and weight of the resisting wedge against the lateral displacement of the sleeper. Estimations show that due to an increase in the volume of the shoulder failure wedge, the shoulder resistance in the winged sleeper is approximately 3.2 times greater than that in the conventional one.

\subsection{Comparing the winged sleeper's STPT and LTPT results}

In case of the panel test, in the panels with five, seven, and nine sleepers, $72 \%, 73 \%$, and $69 \%$ increases in resistive forces of the winged tracks were observed, respectively. A comparison of the results of STPT and LTPT showed about $25 \%$ difference in the increased lateral force between these two test results. For a better understanding of this subject, the common load area in ballast should be mentioned. When a sleeper is loaded, it uses the entire capacity of the shoulder failure wedge which is created at the end of the sleeper. When multiple sleepers are loaded, a part of ballast endures the lateral loads of two sleepers, leading to decreased resistance of each frame sleeper compared with a single sleeper. On the other hand, upon an increase in the sleeper width, the common loading area will be greater, which results in a greater resistance reduction of each sleeper in the panel, as shown in Figure 16.

According to Figure 16 and considering a greater percentage of lost resistance in the winged sleeper, the difference in the results obtained from single sleeper test and panel displacement test appears rational. This fact also applies to crib ballasts, in which almost all the crib ballast is also loaded by the adjacent sleeper. 

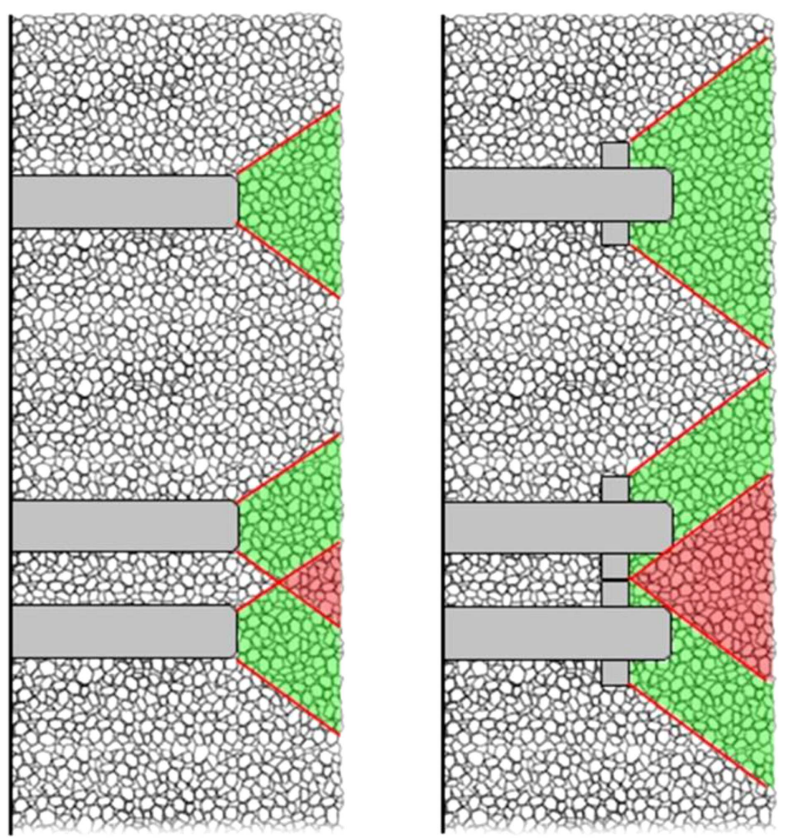

Figure 16. Common loading area in conventional and winged sleepers.

\subsection{Comparing the results of winged and mixed panels}

According to Figure 15, mixed panels formed by five, seven, and nine sleepers experienced $61 \%, 59 \%$, and $57 \%$ increases, respectively, in lateral resistance force compared with the conventional sleepers. Comparison between winged panels (with the average increase of $71 \%$ ) and mixed panels (with the average increase of $59 \%$ ) showed $12 \%$ difference in the lateral resistance increase rate. Crib ballast's capacity played an important role in providing the mixed panel's lateral resistance. Comparison of the ballast failure wedge created in the mixed track and that of winged track showed that a large part of the ballast's capacity was used. There was low lost resistance in this case. In fact, when all the sleepers were substituted with winged sleepers, the common loading area was increased, which resulted in a relatively low increase in fully winged tracks compared with mixed tracks. In Figure 17, the resistant ballast is shown for both of the cases.

\subsection{Effects of sleepers' numbers on the track's panel resistance}

Effect of sleepers' numbers on lateral resistance was also examined in this paper. For a better comparison, each sleeper's lateral resistance for different tested panels is recorded in Table 4.

The resistance measured for each sleeper in Table 4 was obtained by dividing the total resistive force by the number of sleepers. In reality, resistive force in side sleepers is greater than in other sleepers. Also, in mixed panels, depending on the sleeper's type and location in the panel, the resistive force will be different. However, this examination aimed to make these cases comparable. Also, the number attributed to resistive force in STPT in the mixed track was the average number of conventional and winged sleepers.

Figure 18 shows the amount of decrease in each sleeper's resistive force according to the number of sleepers in the panel. This figure was obtained by dividing the resistive force attributed to each sleeper in the panel by the resistive force of a single sleeper. In this diagram, $N_{s}$ is the number of the panel's sleepers, $R_{S T P T}$ is the resistive force in STPT, and $R_{E S P}$ is the resistive force of each sleeper in the panel.

Figure 18 determines that by using the mixed layout, a slight decrease in lateral resistance force will be seen. This issue marks the optimized usage of crib ballast and shoulder's capacity in the mixed layout, compared with conventional and winged layouts.

\section{Conclusion}

Increased load and speed of the rolling stock, necessity of the continuity of tracks, existence of sharp curves (the curves with the radius of less than $400 \mathrm{~m}$ ), and longitudinal loads due to thermal changes have promoted the importance of the rail track's lateral stability. Increasing the rail track's stability is possible by reinforcing the lateral resistance mechanisms. Im-
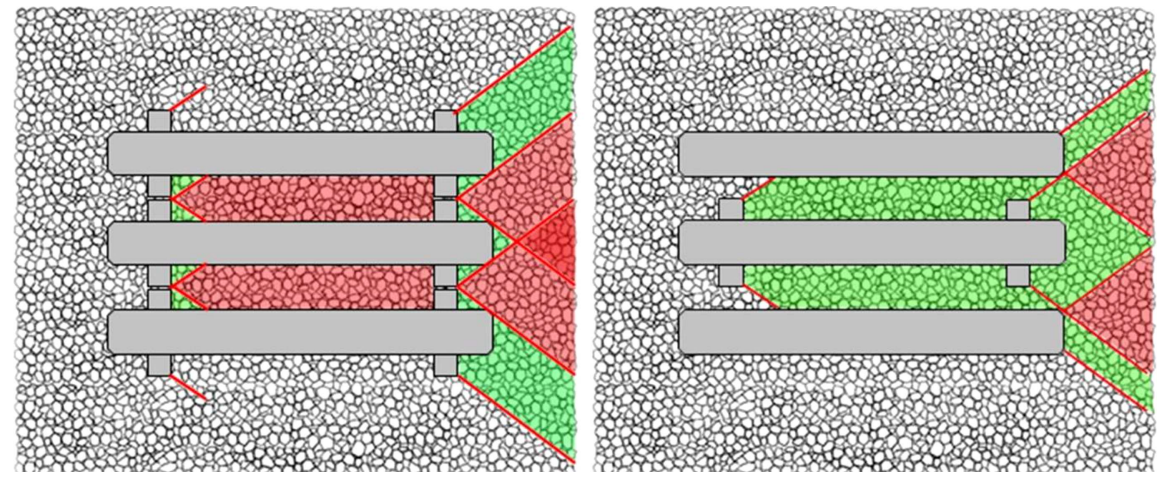

Figure 17. Lateral loading of shoulder and crib ballast in winged and mixed panels. 
Table 4. Average lateral resistance force of every sleeper in different tests $(\mathrm{kN})$.

\begin{tabular}{lccccc}
\hline Track type $\boldsymbol{\nabla}$ & Test type $\boldsymbol{1}$ & $\begin{array}{c}\text { 1 sleeper } \\
\text { (STPT) }\end{array}$ & $\begin{array}{c}\text { 5 sleepers } \\
\text { (LTPT) }\end{array}$ & $\begin{array}{c}\text { 7 sleepers } \\
\text { (LTPT) }\end{array}$ & $\begin{array}{c}\text { 9 sleepers } \\
\text { (LTPT) }\end{array}$ \\
\hline Conventional & 6.59 & 3.44 & 3.20 & 2.89 \\
Mixed & 9.75 & 5.53 & 5.09 & 4.54 \\
Winged & 12.92 & 5.91 & 5.54 & 4.90 \\
\hline
\end{tabular}

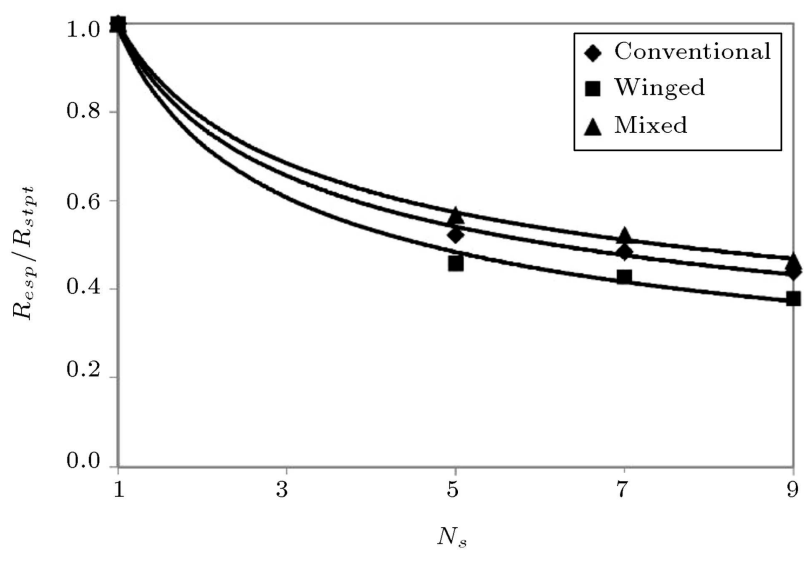

Figure 18. Amount of decrease in each sleeper's resistance force according to panel's number of sleepers.

provement of the passive pressure mechanism of ballast and friction of sleepers' bottom and sides is possible by changing the material, shape, and dimensions of the track components. Moreover, it is also applicable using technologies that stabilize the ballast layer. This study introduced the winged sleeper as a specific type of the sleeper and examined its lateral resistance by laboratory and field tests. Using the winged sleeper in tracks decreased the lateral displacements by increasing the volume of shoulder and crib ballast, which led to two mechanisms of passive pressure and friction. In this study, laboratory and field tests performed on the conventional and winged sleeper Single Sleeper (Tie) Push Test (STPT) showed 101 and 96\% increases in the lateral resistance of $\mathrm{B} 70 \mathrm{w}$ compared with $\mathrm{B} 70$ sleepers. Also, LTPT field tests showed average lateral resistance increases of 71 and $59 \%$ for the fully winged and mixed sleepers (alternating between winged and conventional), respectively. In this work, the ballast capacity was used better in the mixed layout. According to the lateral resistance force of the panels with winged and mixed sleepers, it was found that the capacity of the crib ballast was very important in providing the lateral resistance of the mixed panel. A large part of crib ballast capacity was observed by comparing the passive wedge formed in the mixed track with the one formed in the full-winged one. Moreover, the lost resistance of the shoulder and crib ballast caused by the simultaneous loading zone effects of adjacent sleepers in mixed panels was lower than that of winged panels. Consequently, selecting a mixed panel can be a more economical option to provide lateral resistance by taking into account the economic aspects, the higher resistance of the winged panel, and its slight difference with other panels.

\section{Nomenclature}

STPT Single Sleeper (Tie) Push Test

LTPT Lateral Track Panel loading Test

B70w Winged type of B70 sleeper

DTS Dynamic Track Stabilizer

CWR Continuous Welded Rails

SRE School of Railway Engineering

$\mathrm{R}_{\mathrm{STPT}} \quad$ Lateral resistance force in STPT

$\mathrm{R}_{\mathrm{ESP}} \quad$ Lateral resistance force of each sleeper in panel loading test

\section{References}

1. Zakeri, J.A. "Lateral resistance of railway track", In Reliability and Safety in Railway, X. Perpinya, Ed., INTECH Open Access Publisher, pp. 357-374 (2012).

2. Zakeri, J.A., Mohammadzadeh, S., and Barati, M. "New definition of neutral temperature in continuous welded railway track curves", Period. Polytech. Civ. Eng., 62(1), pp. 143-147 (2018).

3. Kish, A., Samavedam, G., and Wormley, D., Fundamentals of Track Lateral Shift for High-Speed Rail Applications, United States. Federal Railroad Administration (2004).

4. Le Pen, L.M. and Powrie, W. "Contribution of base, crib, and shoulder ballast to the lateral sliding resistance of railway track: a geotechnical perspective", Proc. Inst. Mech. Eng. Part F J. Rail Rapid Transit, 225(2), pp. 113-128 (2011).

5. Profillidis, V.A., Railway Management and Engineering, Ashgate Publishing Limited (2014).

6. Zakeri, J.A., Mirfattahi, B., and Fakhari, M. "Lateral resistance of railway track with frictional sleepers", Proc. ICE - Transp., 165(2), pp. 151-155 (2012).

7. Zakeri, J.A. and Talebi, R. "Experimental investigation into the effect of steel sleeper vertical stiffeners on railway track lateral resistance", Proc. Inst. Mech. Eng. Part F J. Rail Rapid Transit, 231(1), pp. 104-110 (2017). 
8. Sabaghi, S. "Investigation of track lateral resistance with anchored concrete sleepers", BSc Thesis, Iran University of Science and Technology (2013).

9. Jing, G., Qie, L., Markine, V., and Jia, W. "Polyurethane reinforced ballasted track: Review, innovation and challenge", Constr. Build. Mater., 208, pp. 734-748 (2019).

10. Pucillo, G.P., De Iorio, A., Rossi, S., and Testa, M. "On the Effects of the USP on the Lateral Resistance of Ballasted Railway Tracks", 2018 Joint Rail Conference, Paper No: JRC2018-6204, V001T01A017 (2018).

11. Indraratna, B., Nimbalkar, S., Christie, D., Rujikiatkamjorn, C., and Vinod, J. "Field assessment of the performance of a ballasted rail track with and without geosynthetics", J. Geotech. Geoenvironmental Eng., 136(7), pp. 907-917 (2010).

12. Darkhosh, M. "Field investigation on the effect of baby gabions on lateral resistance of ballasted railway tracks", MSc Thesis, Iran University of Science and Technology (2014).

13. Esmaeili, M., Zakeri, J.A., and Babaei, M. "Laboratory and field investigation of the effect of geogridreinforced ballast on railway track lateral resistance", Geotext. Geomembranes, 45(2), pp. 23-33 (2017).

14. Kabo, E. "A numerical study of the lateral ballast resistance in railway tracks", Proc. Inst. Mech. Eng. Part F J. Rail Rapid Transit, 220(4), pp. 425-433 (2006).

15. Zakeri, J.A., Esmaeili, M., Kasraei, A., and Bakhtiary, A. "A numerical investigation on the lateral resistance of frictional sleepers in ballasted railway tracks", Proc. Inst. Mech. Eng. Part F J. Rail Rapid Transit, pp. 110 (2014).

16. Sussmann, T., Kish, A., and Trosino, M. "Influence of track maintenance on lateral resistance of concrete-tie track", Transp. Res. Rec. J. Transp. Res. Board, 1825, pp. 56-63 (2003).

17. Kerr, A.D. Fundamentals of Railway Track Engineering, Simmons-Boardman Books, Incorporated (2003).

18. Klugar, K. "A contribution to ballast mechanics", Railr. Track Mech. Technol., A.D. Kerr, Ed., Pergamon Press, pp. 387-404 (1978).
19. Montalbán Domingo, L., Real Herraiz, J.I., Zamorano, C., and Real Herraiz, T. "Design of a new high lateral resistance sleeper and performance comparison with conventional sleepers in a curved railway track by means of finite element models", Lat. Am. J. Solids Struct., 11(7), pp. 1238-1250 (2014).

20. Koike, Y., Nakamura, T., Hayano, K., and Momoya, Y. "Numerical method for evaluating the lateral resistance of sleepers in ballasted tracks", Soils Found., 54(3), pp. 502-514 (2014).

21. Esmaeili, M., Nouri, R., and Yousefian, K. "Experimental comparison of the lateral resistance of tracks with steel slag ballast and limestone ballast materials", Proc. Inst. Mech. Eng. Part F J. Rail Rapid Transit, 231(2), pp. 175-184 (2017).

22. Le Pen, L., Bhandari, A.R., and Powrie, W. "Sleeper end resistance of ballasted railway tracks", J. Geotech. Geoenvironmental Eng., 140(5), p. 04014004 (2014).

23. Zakeri, J.A. and Bakhtiary, A. "Comparing lateral resistance to different types of sleeper in ballasted railway tracks", Sci. Iran., 21(1), pp. 101-107 (2014).

\section{Biographies}

Jabbar-Ali Zakeri received his $\mathrm{PhD}$ degree in Road and Railway Engineering from Beijing Jiaotong University, China in 2000. Dr Zakeri is currently a Professor at the School of Railway Engineering, Iran University of Science and Technology. His research interests include dynamic analysis of train-track interaction, railway track dynamics, and track maintenance and construction.

Hamid Hassanrezaei received his MSc degree in Railway Engineering from Iran University of Science and Technology, Tehran, Iran in 2015. His research interests include analysis of railway tracks and track maintenance and construction. 